\title{
MAPPING AT DEPTH: A CASE-STUDY OF DIGITAL VIDEO-FRAME PHOTOGRAMMETRY APPLIED TO UNDERWATER ARCHAEOLOGY
}

\author{
Rodrigo de Oliveira Torres ${ }^{i}$
}

Resumo: Este artigo apresenta um estudo de caso sobre os procedimentos da fotogrametria digital aplicada para registrar e reconstruir uma âncora afundada em um naufrágio do século XVII no Brasil. Descreve um fluxo de trabalho direto, usando quadros fixos extraídos automaticamente de vídeos, processados com software, resultando em um modelo 3D em escala 1: 1 altamente preciso. $O$ autor avalia os resultados em termos de eficiência de tempo, precisão da técnica e suas aplicações na arqueologia subaquática. Palavras-Chave: Arqueologia Subaquática; Fotogrametria com vídeo; Mapeamento 3D; Naufrágios.

\begin{abstract}
This paper presents a case-study of applied digital photogrammetry to record and reconstruct a sunken anchor from a 17th century shipwreck site in Brazil. It describes a straightforward workflow using still frames automatically extracted from video footage, processed with off-the-shelf software, resulting in a highly accurate 1:1 scaled 3D model. The author assess the results in terms of time efficiency, accuracy of the technique, and its applications to underwater archaeology. Key Words: Underwater Archaeology; VideoFrame Photogrammetry; 3D Mapping; Shipwrecks.
\end{abstract}

i Centro de Investigaciones del Patrimonio Costero (CIPAC); Centro Universitario de la Región Este. 
Introdução

Mapping methodologies have been a central concern in the technicalities of underwater archaeology since it emerged as a scientific field in the early 1960's (Bass, 1966; Throckmorton, 1969). Initially, the methodological paradigm of the nascent discipline was marked by the search to replicate the same techniques and procedures employed by land excavations for underwater sites. In consequence, large hard-framed rigs, cumbersome photography towers, leveling rods and survey transits, among other instruments, were successfully adapted for tridimensional mapping of underwater sites (Green et al., 1971; Baker and Green, 1976; Green, 1990; Martin and Martin, 2002).

The deployment of rigid grids and tridimensional (3D) tape measure surveys underwater, however, can be very time-consuming, posing an array of logistic, safety and accuracy challenges (Rule, 1989; Holt, 2003; Van Damme, 2015: 231). In addition, a different set of physical, physiological and psychological factors, such as limited air supply, visibility constrains, water temperature, poor communication and hyperbaric illnesses concern the archaeologist diver, reducing workable time underwater and potentially affecting accuracy of the results (Rule, 1995: 51; Bowens, 2009: 40-42). These intrinsic limitations of working underwater have led archaeologists to constantly look for more efficient and accurate mapping techniques, such as photogrammetry, placing underwater archaeology in the forefront in terms of the development of innovative recording strategies.

Closely following the beginning of the discipline, photogrammetry was first experimented with underwater archaeology in the 1960's and 70's, during shipwreck surveys and excavations led by American underwater pioneer George Bass and the Institute of Nautical Archaeology at Yassiada, Turkey (Bass, 1966; Bass and Rosencrantz, 1972; Rosencrantz, 1975). In these surveys, a number of different approaches were tested, involving the use of synchronized film cameras placed in waterproof housings, and mounted along rails to shoot rows of overlapping stereo pairs, a technique therefore called stereophotogrammetry. In the wake of these first experiments, the applications of underwater photogrammetry for archaeology increased more or less steadily during the following decades, in parallel with the growing interest in underwater archaeology around the Mediterranean area and the developments in underwater 
photography rigs (Ciani et al., 1971; Faig, 1979; Hoehle, 1971; Polio, 1968; 1971; Liou, 1973; Tchernia et al., 1978).

Nevertheless, before digital hardware and software became widely available, photogrammetry was highly specialized, requiring the participation of technical experts and dedicated equipment, thus preventing it from reaching the archaeology mainstream (Van Damme, 2015). With the introduction and dissemination of digital cameras and sensors, powerful yet affordable computers and software, digital photogrammetry is now becoming routine in archaeological surveys, and every season new underwater projects are incorporating it in various recording strategies (Mahon et al., 2011; Drap, 2012; Zhukovsky et al., 2013; McCarthy and Benjamin, 2014; Yamafune et al., 2016, to cite a few).

Digital photogrammetry is referred to here as set of techniques used to accurately reconstruct geometries and relative position of features in a scene from a group of digital photographs taken from different positions, allowing for measurements and spatial manipulation in realscale tridimensional realms. Since 2012, the author with a team in the Ship Reconstruction Laboratory (SHIPLab) at Texas A\&M University have turned to digital photogrammetry and modeling as the primary technique to record shipwreck sites, due to its ease of use, high accuracy, fast data acquisition, and flexibility in facilitating digitally-born products (Torres, 2015; Yamafune, et al., 2016; Yamafune, 2016).

This paper thus presents a case-study of digital photogrammetry applied to record and reconstruct a sunken anchor from a 17th century shipwreck site in Brazil. It describes a straightforward workflow using still frames automatically extracted from video footage, processed with off-the-shelf software, resulting in a highly accurate 1:1 scaled 3D model. The author asses the results in terms of time efficiency, accuracy of the technique, and its applications to underwater archaeology.

\section{Project Background}

In December 2012, an international team of underwater archaeologists supported by the Dutch Cultural Heritage Agency, the Nautical Archaeology Program at Texas A\&M University and the Museu de Arqueologia e Etnografia from Universidade Federal da Bahia in Brazil recorded the underwater wreck remains of a naval combat between Dutch and Portuguese ships, which took place in the Atlantic waters off northeast Brazil in 1648 (Torres and Castro, 
2012; Manders and Brouwers, 2016). The site consists of scattered remains of two sunken men-of-war, the Dutch ship Utrecht and the Portuguese Nossa Senhora do Rosário. The artifacts preserved there include large anchors, canons, ballast piles and hull timbers, spreading across approximately 200 meters of the seabed, at a depth of water of 22 meters (Figure 1). Tape measurements, 3D trilateration and computer modelling were used to survey the wreck site, producing rich $2 \mathrm{D}$ and $3 \mathrm{D}$ documentation, allowing for more precise studies in nautical archaeology and site preservation.

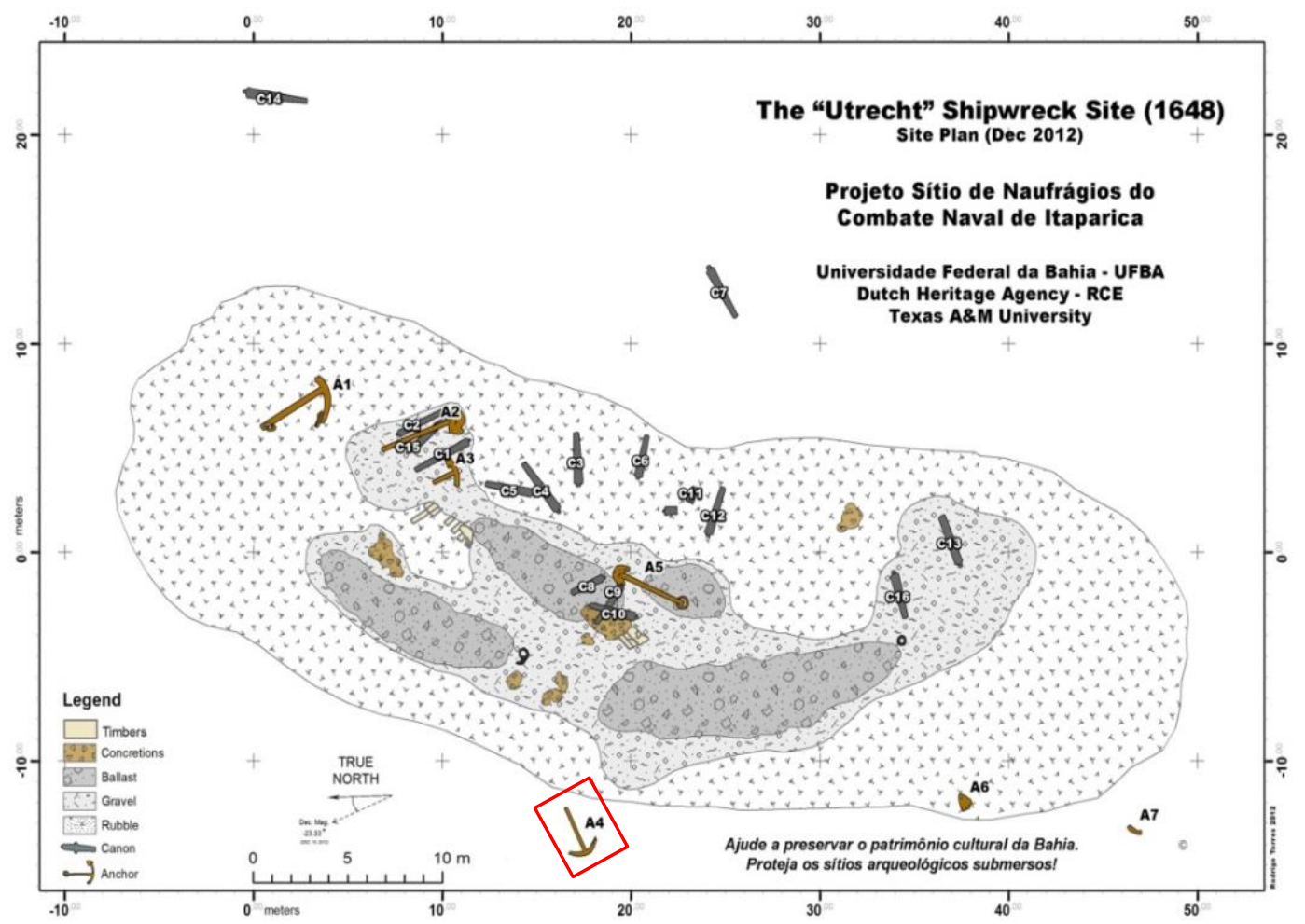

Figure 1: Site plan of the Utrecht (1648) shipwreck site. The mapped anchor (A4) is marked by the red square.

In August 2015, the author returned to the site to experiment with digital photogrammetry in the course of the project: "Archaeology and Computer Graphics: Developing a Digital Museum of a Maritime Landscape in Brazil". This project builds upon recent developments in maritime archaeology and computer graphics to propose an approach to the problem of heritage preservation involving the application of in situ management strategies, coupled with computer graphics and tridimensional modeling for digital preservation and public sharing (http://www.observabaia.ufba.br/pesquisas-e-producao/patrimonio-cultural-subaquatico/). 


\section{Workflow}

Working with digitally-born data requires a number of extra steps which must be considered together when planning a survey. General steps include Planning, Data Acquisition, Data Processing, Storage, Post-processing and Deliverables. These general guidelines, however, must be 'tweaked' according to actual project resources and goals. Since a broader perspective on the general workflow developed at the SHIPLab for the use of photogrammetry for recording, reconstructing and interpreting shipwrecks has already been discussed elsewhere (Yamafune et al., 2016), the following diagram focus on the specific sequence of operations used in this case-study (Figure 2).

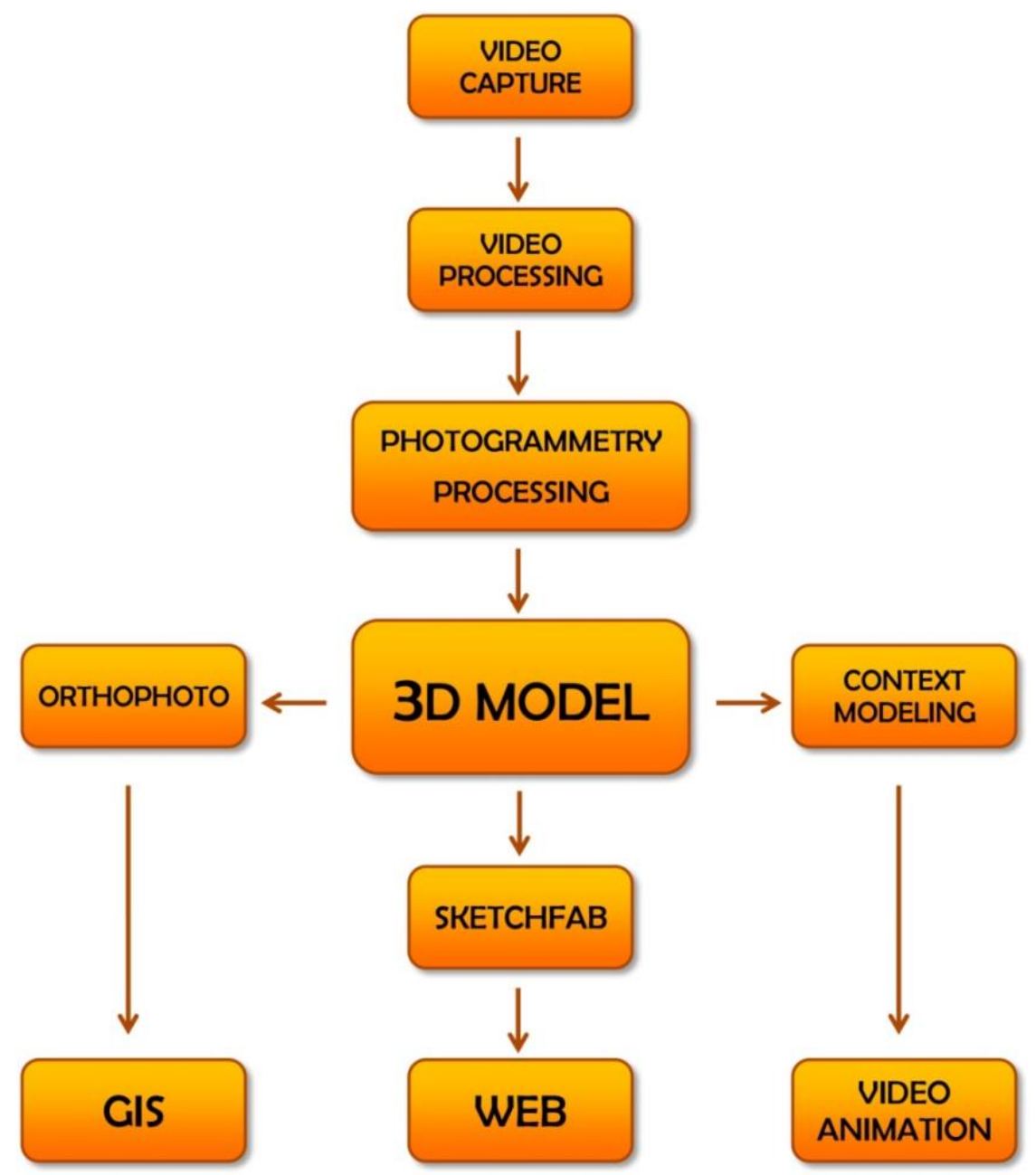

Figure 2: Workflow diagram connecting the sequence of operations followed in this case-study. 


\section{Material and Methods}

This case-study is based on the results of one diving session with two divers to record anchor number 4 at the archaeological site of the Dutch ship Utrecht. During a 35 minutes dive, an area of $5 \times 4$ meters was recorded on video by a free swimming diver using conventional SCUBA gear.

The camera used was a GoPro model HERO 4 Silver fitted in a standard GoPro underwater housing, with no external video lights, and mounted on an ' $L$ ' shaped aluminum bar with handles for improving steadiness. A laptop computer running an Intel Core i7-3520M processor CPU @2.90GHz, Intel HD Graphics 4000, and 8GB installed RAM memory on Windows 7 64-bit operational system was used for data processing. The program used for video editing was the GoPro Studio version 2.5.7, which is freely available for download at the GoPro website. Adobe Photoshop CS6 was used for automated video frames extraction, and Agisoft PhotoScan Professional version 1.2.1 build 2278 used for 3D model processing and exporting.

In order to provide the created models with correct 1:1 scale, six one-meter long aluminum bars were cut and fitted with uniquely identified 12-bit coded targets. The targets, available for download from PhotoScan documentation files, were printed out on waterproof adhesive paper, glued onto a hard plastic background and laminated. Two targets were then fixed on each bar, and distances between them measured carefully with a steel measuring tape. Once underwater, the scale bars were conveniently positioned around the main scene to be surveyed, defining a target area of approximately $20 \mathrm{~m} 2$.

An efficient data acquisition plan for diver-based underwater photogrammetry must take in consideration available dive time, characteristics of the camera and water visibility. For this case-study, we had two divers working at $22 \mathrm{~m}$ with a planned total dive time of 35 minutes, including descending, placing the aluminum bars, shooting video, retrieving the bars, and ascending to the surface with a 3 minute safety decompression stop at $5 \mathrm{~m}$. The camera was set to capture video in HD 1080p mode at 30 frames per second (fps) with wide field of view (fov), which according to the manufacturers is equivalent to 170 degrees. Horizontal visibility during the dive was good, approximately $20 \mathrm{~m}$, and swimming height above seabed was kept at 0.85 meters on average. 
After the dive, the video file was downloaded in MP4 format (H.264 codec) from the camera into GoPro Studio software, where unwanted video sequences were edited out. The resulting video file had 1.81 GB of data and was imported into Photoshop using the 'Video to Layers' import command. At this point, the desired number of layers corresponding to video frames to be automatically extracted must be chosen.

Taking into account that each feature to be reconstructed in the 3D model must be visible in at least two images, a critical element for good geometry reconstruction is the amount of overlap between frames. For top view imagery, software requirements indicate a good overlap must be around $80 \%$ forward and $60 \%$ between rows (Agisoft LLC, 2016: 5). In this case-study, considering that the video file had a total time of 11:24 minutes, and was shot in $30 \mathrm{fps}$, we chose to sample one every 45 frames, which produced 458 still images with roughly $80 \%$ forward overlap. Since diver swimming speed and height above the seabed were not constant, some trial-and-error was necessary to get to an appropriate overlapping.

Using the 'Layers to File' script in Photoshop, the extracted video frames were exported as individual TIFF files (5.6 MB each), and uploaded into PhotoScan for geometry building, texturing and exporting. Once the sampled video frames were loaded into PhotoScan, they were inspected for sharpness using the 'Estimate Image Quality' tool. As a result, the software returns a quality assessment index and any photo with an index value equal or inferior to 0.5 must be disabled before further processing (Agisoft LLC, 2016: 12). Since photogrammetric model processing largely followed the guidelines presented in PhotoScan General Workflow (Agisoft LLC, 2016: 8), we will now mainly focus on the particular settings and procedures applied in this case-study.

The first step for model building is camera positions alignment. During this stage, the software searches for and matches common points between frames, as well as spatially locates the camera position for each shot, resulting in a sparse point cloud. An aspect of this video frame technique is that no camera properties, such as sensor size or focal length, are embedded in the files EXIF metadata. Therefore, PhotoScan initially assumes a default $50 \mathrm{~mm}$ focal length, deriving all camera calibration parameters during photo alignment calculations.

After alignment, it is advisable to adjust the model's bounding box in order to restrict calculation power to a desired target area before proceeding into the next steps, and to conveniently orient the model in the 3 axis $(X, Y, Z)$. The author found that the best procedure 
to orient and define the bounding box of a model which has not been referenced with coordinates is first to set it to top orthographic view, then use the 'Rotate Object' tool to define its orientation accordingly and adjust the bounding box using both the 'Rotate Region' and 'Resize Region' tools. Repeat the process for left view and finally for front view, and save the project.

Since coded targets had been placed in the scene underwater, we used the built-in 'Detect Markers' tool in order to have them automatically recognized by PhotoScan. Scale bar features were then added by selecting the corresponding pairs of targets on each bar, and previously measured lengths for each bar were entered (Figure 3). These targets can be automatically recognized by PhotoScan and, by fixing them to rigid scale bars, they can be used for model real-world scaling and optimization.

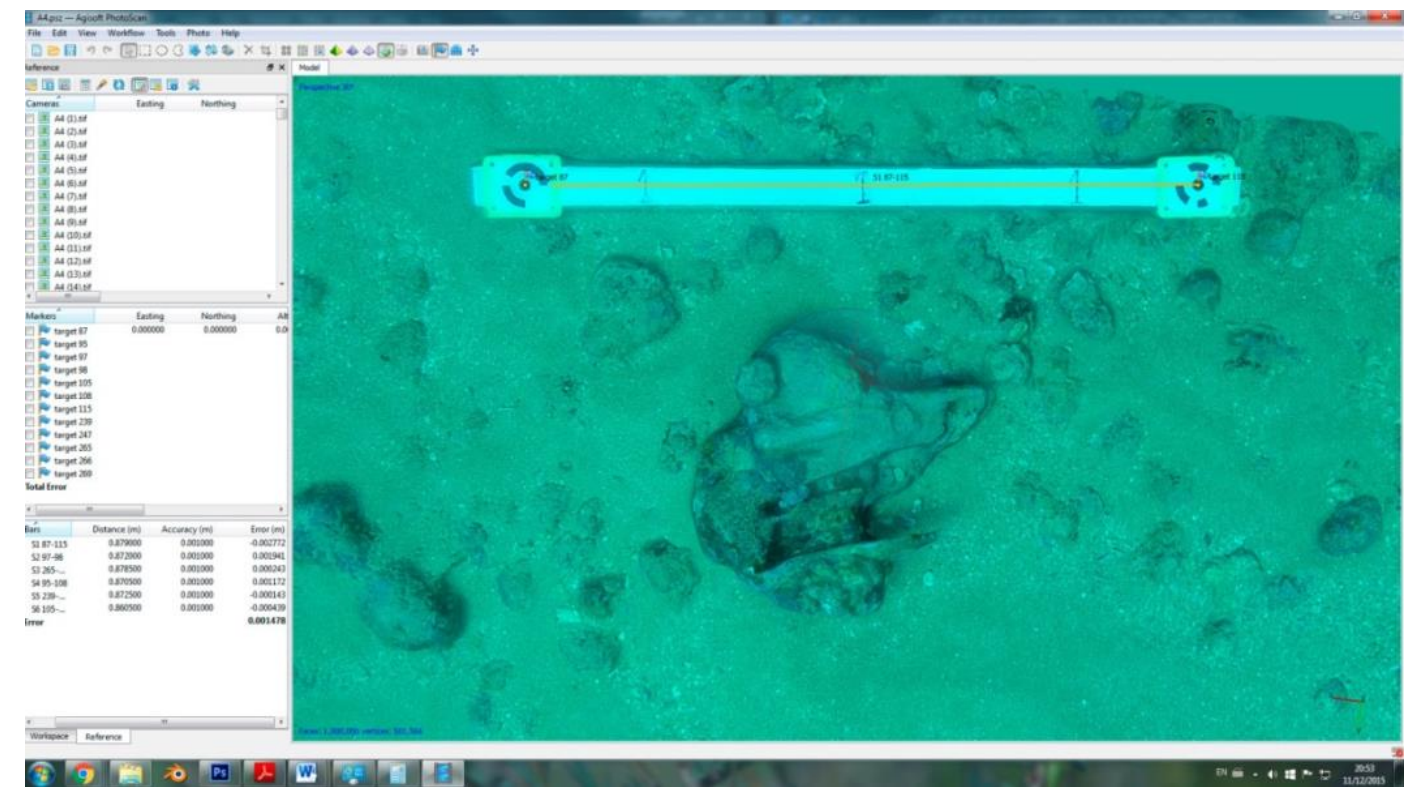

Figure 3: Entering scale bar measurement in between coded targets on the 3D model.

After measured lengths were added for the six scale bars, we proceeded to model optimization. Optimization is a processing step in which internal and external orientation parameters for the various camera positions can be improved, thus potentially minimizing the sum of errors in the final model (Agisoft LLC, 2016: 46). Before optimization, however, it is advisable to check for and delete any evidently spurious points in the cloud.

Next step involves calculating depth information for each camera position, resulting in a dense point cloud which represents the external surface of the scene. It contains $x, y$ and $z$ coordinates, as well as color (RGB) and normal information, for each point in the 3D cloud. 
Furthermore, using the dense point cloud as the data source, a 3D polygonal mesh was built and interpolated for surface geometry reconstruction. In order to have a more manageable file before texturing, the mesh was decimated down to a target number of $1,000,000$ faces. The triangular mesh was then texturized using original frames, producing three texture atlases of $5,000 \times 5,000$ pixels each, saved in JPEG format.

Finally, the texturized model was exported in Wavefront (OBJ) format. The main OBJ file and its auxiliary files, including the materials file (MTL) and texture atlases (JPEG), were zipped for uploading into Sketchfab.com, and embed in the project's website for public sharing (Figure 4). Sketchfab.com is a webGL based platform for uploading and sharing 3D content online free of charge. A high-resolution 2D orthophoto was generated and exported in TIFF format (raster), with an auxiliary World File for spatial reference. The raster file was then loaded into the ongoing project's G.I.S. using ARCMap version 10.4.1 (ESRI, 2016).

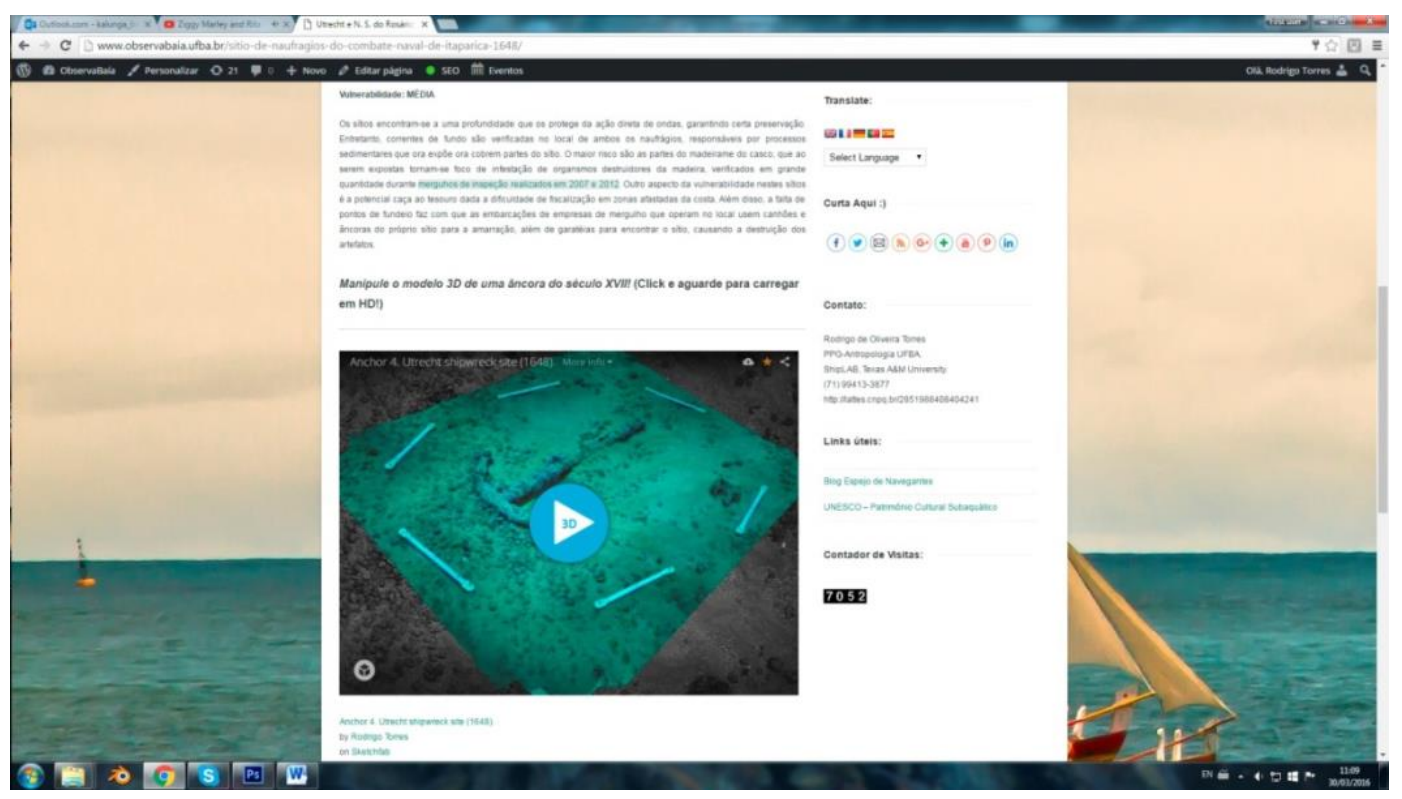

Figure 4: Embedded Sketchfab viewer into the project's website for public sharing.

It is important to highlight the properties and usefulness of 1:1 scale-constrained photogrammetric models as archaeological data. As noted earlier, real world scaled 3D models have correct dimensions, which mean that archaeologists can take highly accurate measurements directly from it, allowing researchers to manipulate and interpret their study subjects. One of the capabilities of the technique is providing reconstructions of the original artifact through context modeling, by using the photogrammetric model as a tridimensional template to create an archaeologically informed idealized reconstruction model (Figure 5). For 
this, the 3D model in OBJ format was imported into AutodeskMaya3D, where various modeling techniques were employed for 3D drawing, attributing material and texture information in order to resemble an 17th century Dutch ship anchor. Afterwards, the model was animated within the software's animation plug-in and exported in Animated GIF format.

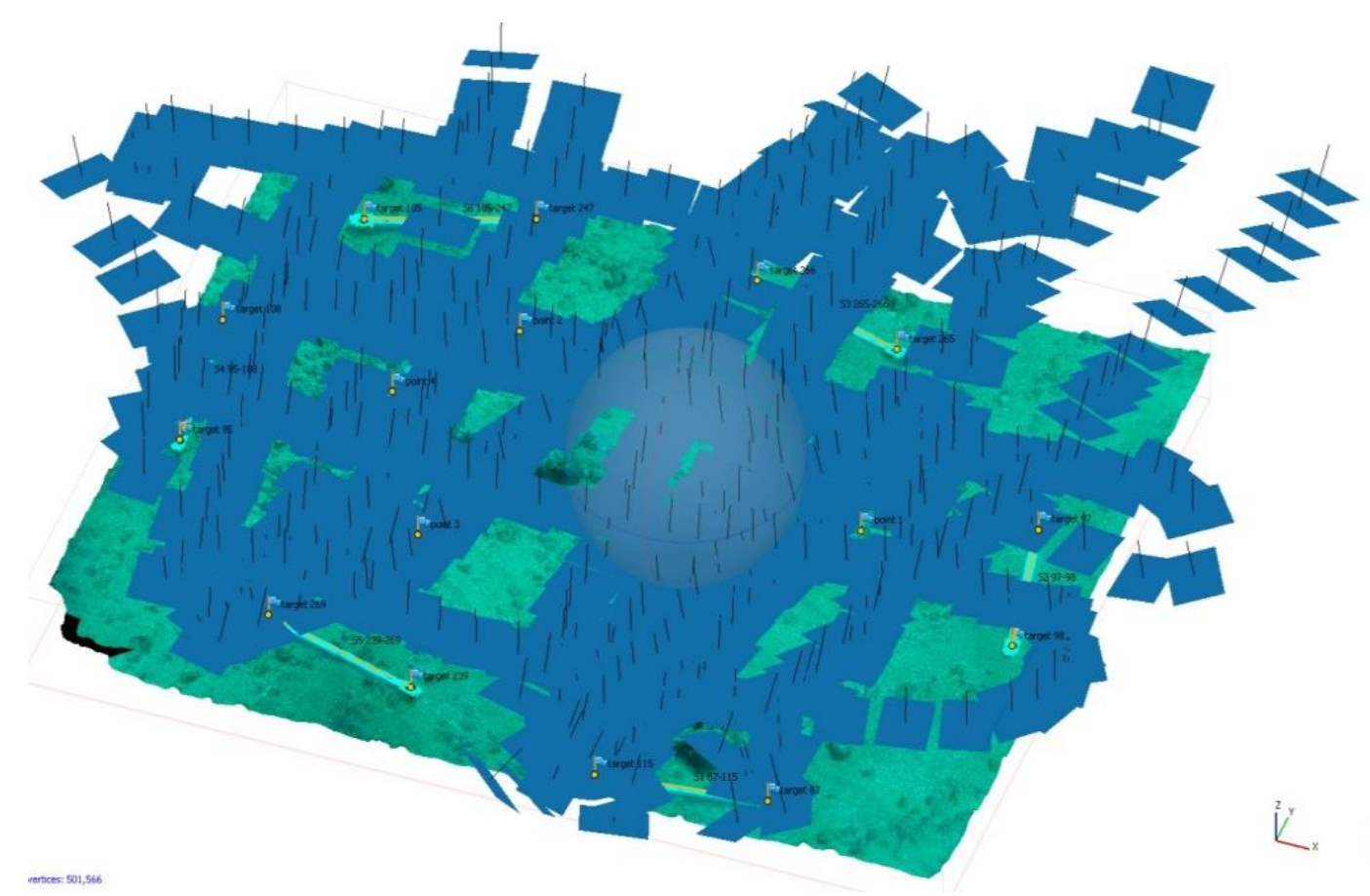

Figure 5: Archaeologically informed reconstruction based on a photogrammetric model (anchor reconstruction by Kotaro Yamafune).

\section{Results and Discussion}

The resulting photogrammetric model contained an exact 1:1 scale-constrained 3D model of a $20 \mathrm{~m} 2$ area, including an anchor and a rigging block (See attached model). The model is highly accurate, capable of representing detailed geometries and textures of the recorded scene. The processing parameters and approximate times corresponding to each one of the main steps in the photogrammetric workflow is summed up in Table 1.

Therefore, total photogrammetric workflow time was roughly 285 minutes, with 35 minutes for data acquisition (12\%) and 250 minutes for data processing (88\%). This ratio between data acquisition and processing time clearly shows the value of the technique whenever data collecting time is at a premium, such as in underwater archaeology. Most of the workflow 
time, approximately $52 \%$, was spent in photo alignment, a processing step which demands significant computing power for calculations.

Table 1: Main steps and approximate corresponding times for the photogrammetric processing workflow.

\begin{tabular}{|c|c|c|c|}
\hline & STEP & PARAMETER SETTINGS & TIME (minutes) \\
\hline 옴 & IMPORT VIDEO TO LAYERS & 1 FRAME IN EVERY 45 FRAMES & 7 \\
\hline 움 & EXPORT LAYERS TO FILES & $\begin{array}{l}\text { TIFF } \\
\text { W/O COMPACTING }\end{array}$ & 12 \\
\hline \multirow[b]{8}{*}{ 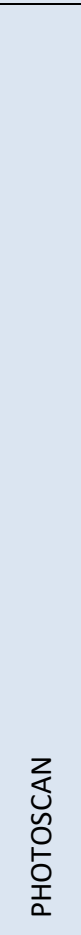 } & ADD PHOTOS & $\mathrm{N} / \mathrm{A}$ & 1 \\
\hline & ESTIMATE PHOTO QUALITY & $\mathrm{N} / \mathrm{A}$ & 2 \\
\hline & ALIGN PHOTOS & $\begin{array}{l}\text { ACCURACY: High } \\
\text { PAIR PRESELECTION: Generic } \\
\text { KEY POINT LIMIT: } 40,000 \\
\text { TIE POINT LIMIT: } 1,000\end{array}$ & 150 \\
\hline & DETECT TARGETS + ADD SCALE BARS & $\begin{array}{l}\text { MARKER TYPE: Circular 12bit } \\
\text { TOLERANCE: } 75 \\
\text { DISABLED PARITY }\end{array}$ & 5 \\
\hline & OPTMIZE CAMERAS & $\mathrm{N} / \mathrm{A}$ & 3 \\
\hline & BUILD DENSE CLOUD & $\begin{array}{l}\text { QUALITY: Medium } \\
\text { DEPTH FILTERING: Moderate }\end{array}$ & 25 \\
\hline & BUILD MESH & $\begin{array}{l}\text { SURFACE TYPE: Arbitrary } \\
\text { SOURCE DATA: Dense cloud } \\
\text { FACE COUNT: } 0 \\
\text { POINT CLASSES: All } \\
\text { INTERPOLATION: Enabled }\end{array}$ & 10 \\
\hline & BUILD TEXTURE & $\begin{array}{l}\text { MAPPING MODE: Generic } \\
\text { BLENDING: Mosaic } \\
\text { TEXTURE SIZE/COUNT: } 5000 \times 3 \\
\text { COLOR CORRECTION ENABLED }\end{array}$ & 35 \\
\hline & \multicolumn{2}{|l|}{ TOTAL TIME } & 250 (04:10 hours) \\
\hline
\end{tabular}

Data acquisition using the GoPro camera in video mode was quite fast and efficient, considering it took just over 11 minutes to cover in detail an area of $20 \mathrm{~m}^{2}$. Since video recording does not require careful camera framing and light metering, using this acquisition technique tends to cover a much larger area in less time than shooting still photos. The author' experience suggests the coverage efficiency using this video frame technique can be up to four times greater than using still photos (Yamafune et al., 2016).

Another advantage of video frame photogrammetry is the high level of control over forward overlapping. In this case-study, shooting in HD 1080p video mode at $30 \mathrm{fps}$ produced over 20,000 potentially useful 2.1 megapixel resolution still frames. Consequently, video frame photogrammetry tends to produce relatively good results in the Align Photos process step. On the other hand, since no structured swimming plan was devised, side overlapping was far from 
ideal. This issue was partially overcome by using wide angle lenses and swimming close to the ground (approx. $0.85 \mathrm{~m}$ ) (Figure 6).

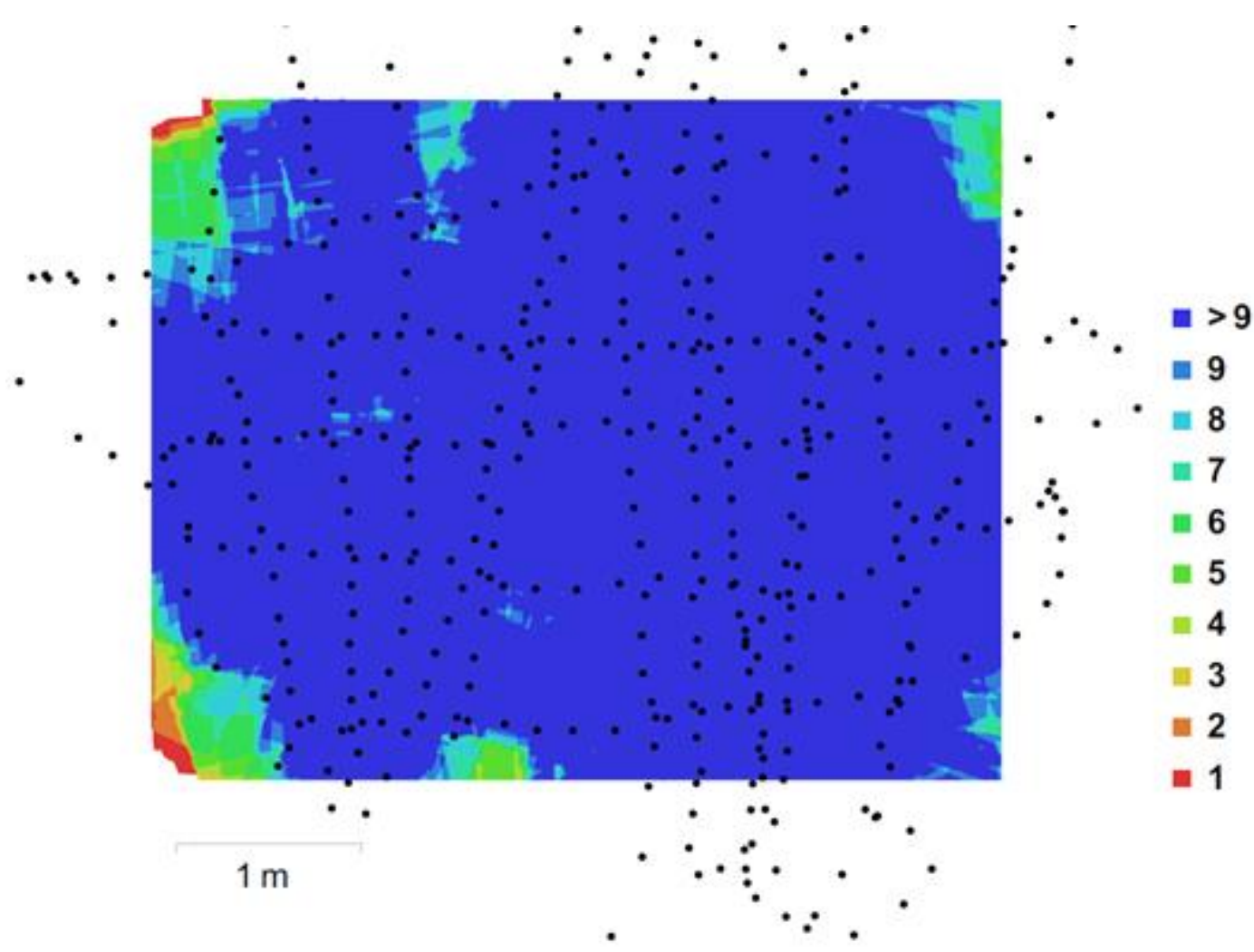

Figure 6: Above: swim pattern, where blue squares represent camera positions for extracted frames. Bellow: color coded overlapping map, representing number of frames covering each part of the scene.

It is also important to note that a frame extracted from a High Definition video is equivalent to a low resolution photograph, and therefore contains a smaller amount of pixel information $(<10 \%)$ than a typical APS-C image sensor from DSLR cameras, thus tending to produce potentially poorer textures in the final model. Nevertheless, by dividing the texture atlas in three files of 5,000 x 5,000 pixels each, a reasonably good textured model can be achieved, wherever sufficient coverage was provided.

As for extracting still frames from video, the downside of automatically sampling over manually selecting frame by frame, for example, is that you may end up with some blurred frames in the dataset. In the proposed workflow, this issue was addressed by using the 'Estimate Image Quality' feature in PhotoScan. Surprisingly, only two frames out of the 458 automatically sampled still frames didn't have enough quality, and had to be disabled before processing. This resulted in a working dataset of 456 useful frames with a quality index of 0.7 or greater. During the alignment stage, 435 frames aligned automatically and the remaining 21 frames had to be aligned manually, resulting in a sparse point cloud with 96,695 points. It 
became evident that a slow and steady swimming pace is crucial for reducing blurriness, consequently improving photo alignment results as well as model texturing afterwards. As seen in the previous section, coded targets fixed on rigid scale bars were used as a means for optimizing alignment results and accuracy assessment, as well as to provide the model with real world dimensions. In this case-study, the sum of errors for the six scale bars, that is, the sum of the differences between input scale bar lengths and the measured lengths in the processed model, was $0.019608 \mathrm{~m}$ before optimization. After optimization using the scale bars with targets technique, the sum of differences was lowered to $0.002540 \mathrm{~m}$, nearly one order of magnitude smaller than prior. This result highlights the importance of the scale bars method and optimization, particularly in cases when metadata is insufficient or nonexistent, or when other instruments for position fixing are not available but high accuracy real-world scaling is needed.

Positioning the targets and scale bars during scene preparation underwater, however, requires some experience in knowing the expected results for the final model. In this particular casestudy, scene preparation was facilitated since the anchor laid flat against the seabed, hence no extreme concave or convex geometries were present, eliminating the need for more elaborated target placement and data acquisition strategy. Targets were automatically detected in most frames, but manual target positioning adjustments were necessary in approximately $15 \%$ of them.

Once camera orientations were successfully optimized, the remaining processing steps became straightforward. Dense cloud processing resulted in a single dense cloud with 4,881,780 points, and mesh building generated an extremely detailed surface model with 7,876,391 faces, further decimated down to 1,000,000 faces for ease of handling. In this case-study, the mesh model was processed with interpolation enabled, which means that the software algorithm automatically closed any holes in the mesh resulting from poor image coverage. Consequently, the lack of adequate coverage in some concave areas resulted in localized poor surface representation and texture blurriness (Figure 7). Based on our experience in other photogrammetry projects, this issue could be rather easily fixed by recording these areas more carefully, including the use of oblique image acquisition and more refined target placement.

The final textured model preserved a great amount of fine surface detail. However, due to the absence of external lights during video shooting, the still frames, and therefore the final texture, presented an overall greenish look. It happened because at $22 \mathrm{~m}$ most of the color 
tones in the wavelengths of red, orange and yellow had already been absorbed through the water column. Refined techniques for computational color correction of underwater photographs have been thoroughly discussed in Bianco et al. (2015).

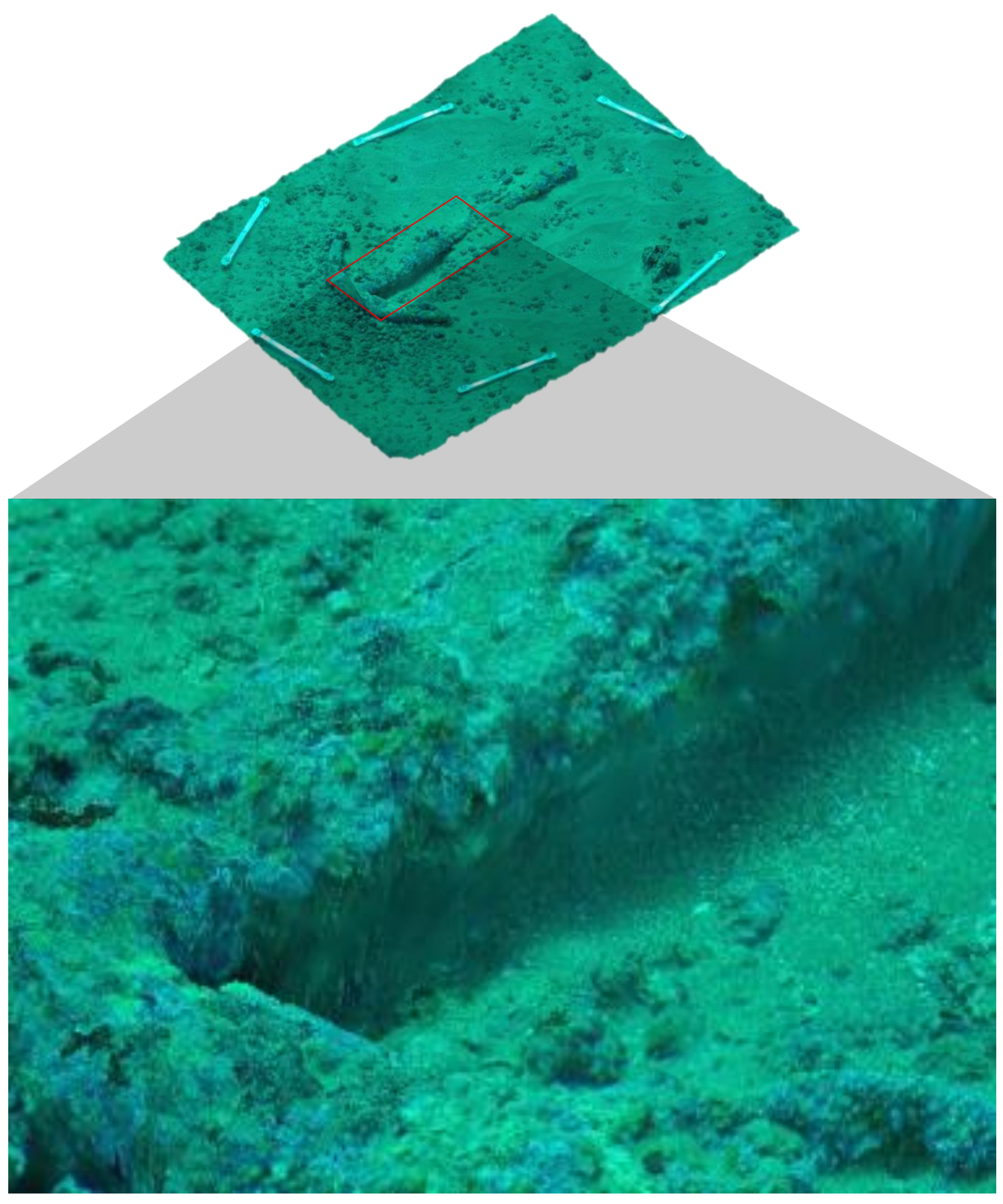

Figure 7: Detail showing poor texturing resulting from poor video coverage.

In short, photogrammetric models greatly help archaeologists to reconstruct the original shapes of study subjects, and those reconstructed shapes, or 3D reconstruction models help archaeologists to understand functions when it was being operated in the past. 


\section{Conclusions}

This paper presented a straightforward workflow based on digital photogrammetry to record and publicly share submerged cultural heritage. The described set of novel techniques using still frames from video footage, thus called Video Frame Photogrammetry, can be deployed to produce highly accurate 1:1 scaled 3D models underwater, using affordable equipment, manageable logistics and minimum expert knowledge.

As seen, the video frame technique has both advantages and disadvantages. In the pro side we can emphasize the greater overlapping between consecutive frames, which is a key element for photogrammetry, particularly during the alignment stage. Furthermore, given the easiness of video recording over conventional photo shooting with strobes, a diver can cover larger areas with minimum technicalities. It is, doubtless, the technique of choice for the archaeologist diver conducting pre-disturbance surveys. Moreover, the workflow presented in this case-study can be deployed when in-field partial results are needed for decision making during excavations and surveys.

On the other hand, the low resolution still frames extracted from HD videos contain a relatively small amount of pixel information, which can be critical in less-than-ideal conditions, such as in poor visibility, or when high quality textures are needed. Nevertheless, the resulting model generated in this case-study was quite accurate, with high resolution and generally good visual fidelity, thus able to represent fine details of the recorded area.

The GoPro camera is small and very versatile, relatively cheap, offering various automated capture settings. Easy usage is definitely a convenient feature for expeditious underwater recording, since it enables divers to focus on buoyancy control, swimming pace and height, rather than camera handling. In addition, it could be easily mounted on ROV's, AUV's or diverheld underwater scooters. Planning the dive was quite straightforward and it did not require special gear deployments, since the scale bar method is a very versatile resource for scaling the model.

In short, Video Frame Photogrammetry can be a good option for photogrammetric recording, especially when a project does not have DSLR cameras or is time-constrained, but accuracy is needed. Nonetheless, the most important point is that whoever applies Video Frame Photogrammetry must understand both the advantages and disadvantages of using video 
footage as the source for photogrammetry. Although not perfect, it offers a good compromise between accuracy and efficiency, and as any other recording technique, the quality of the results must be assessed relatively to the established project goals.

\section{Bibliography}

Agisoft LCC. 2016. Agisoft PhotoScan User Manual: Professional Edition, Version 1.2. Available at: http://www.agisoft.com/pdf/photoscan-pro_1_2_en.pdf (25/07/2016).

BASS, G. F. 1966. Archaeology under Water. New York: Praeger. 224p.

BASS, G. F. and Rosencrantz, D. M. 1972. Submersibles in Underwater Search and Photogrammetric Mapping. In: UNESCO. Underwater Archaeology, a nascent disciplne. Museum and Monuments series, 13: 271-83. Paris.

BAKER, P. E. and GREEN, J. 1976. Recording Techniques Used during the Excavation of the Batavia. The International Journal of Nautical Archaeology and Underwater Exploration. 5.2: 143-158.

BOWENS, A. (ed.). 2009. Underwater Archaeology: The NAS Guide to Principles and Practice. Second Edition. The Nautical Archaeology Society. Blackwell Publishing: United Kingdom. 226p.

CIANI J. B. et al. 1971. Seafloor surveying by divers. In ASCE J Surv Mapp Div, Vol.:97, pp.149-164, isbn/issn: (Ed.) Epub.

DRAP, P., 2012, Underwater Photogrammetry for Archaeology, INTECH Open Access Publisher, Rijeka.

ESRI 2016. ArcGIS Desktop: Release 10.4.1. Redlands, CA: Environmental Systems Research Institute.

FAIG W., 1979. Photogrammetric surveys of underwater objects. In: Proceedings coastal mapping symposium, August 1978, Rockville, Maryland, in (American Society of Photogrammetry, Falls Church, VA) pp.183-187.

GREEN, J. et al. 1971. Simple Underwater Photogrammetry Techniques. Archaeometry. 13, 2: 221-232.

GREEN, J. 1990. Maritime Archaeology: a Technical Handbook. London: Academic Press.

Hoehle J., 1971. Reconstruction of the underwater object. In: Photogrammetry Eng, Vol.:37, pp.948-954.

HOLT, P. 2003. An assessment of quality in underwater archaeological surveys using tape measurements. The International Journal of Nautical Archaeology. 32.2: 246-251.

LIOU B., 1973. Recherches archéologiques sous-marines. in Gallia,Vol.:31, pp.571-608.

MAHON, I, et al., 2011. Reconstructing Pavlopetri: Mapping the World's Oldest Submerged Town using Stereo-vision. IEEE International Conference on Robotics and Automation. Shanghai International Conference Center. Shanghai, China.

MANDERS M.R., and BROUWERS W.F.G.J., (Eds.). The Utrecht (1648), a shipwreck of the Dutch admiralty in the Baía de Todos os Santos, Brazil: its history from battle to archaeological assessment. 1ed. Amersfoort: Cultural Heritage Agency of the Netherlands.

MARTIN, C. J. M and MARTIN, E. A. 2002. An underwater photomosaic technique using Adobe Photoshop. The International Journal of Nautical Archaeology. 31.1: 137-147. 
MCCARTHY J., and BENJAMIN J., 2014, Multi-image Photogrammetry for Underwater Archaeological Site Recording: An Accessible, Diver-based Approach. Journal of Maritime Archaeology 9, 95-114.

POLLIO J., 1968. Application of underwater photogrammetry. In: Naval Oceanographic Office.

POLLIO J. 1971. Underwater Mapping with Photography and SONAR. in Photogramm Eng, Vol.:37, pp.955-968.

ROSENCRANTZ, D. M. 1975. Underwater Photography and Photogrammetry, in: Photography in Archaeological Research, School of American Research Advanced Seminar Series. University of New Mexico Press, Albuquerque, pp. 265-309.

RULE, N. 1989. The Direct Survey Method (DSM) of underwater survey, and its application underwater. The International Journal of Nautical Archaeology and Underwater Exploration. 18.2: 157-162.

RULE, N.. 1995. Some techniques for cost-effective three-dimensional mapping of underwater sites. From Computer Applications and Quantitative Methods in Archaeology Conference, 1993. BAR International Series 598: 51-56.

TCHERNIA, A., POMEY P., HESNARD A. 1978. L'épave romaine de La Madrague de Giens (Var). In: Supplément à Gallia Nº 34.

THROCKMORTON, P. (ed.) 1969. Surveying in Archaeology Underwater. Monography Series, 5, Colt Archaeological Institute. London: Quaritch Ltd. 94p.

TORRES, R. 2015. The Archaeology of Shore Stranded Shipwrecks of Southern Brazil. PhD Dissertation. Nautical Archaeology Program. Anthropology Department. Texas A\&M University, EUA. 181p.

TORRES, R. and CASTRO, F. 2012. The Utrecht Shipwreck Research Effort - Preliminary Report and Catalogue. Mutual Heritage Program RCE, Netherlands and Nautical Archaeology Program, Texas A\&M University, College Station, USA. 42p.

VAN DAMME, T., 2015. Computer Vision Photogrammetry for Underwater Archaeology Site Recording in a Low-Visibility Environment. In: The International Archives of the Photogrammetry, Remote Snensing and Spatial Information Sciences, V. XL-5/W5. Underwater 3D Recording and Modeling. Piano di Sorrento, Italy.

YAMAFUNE, K. 2016. Using Computer Vision Photogrammetry (Agisoft PhotoScan) to Record and Analyze Underwater Shipwreck Sites. PhD Dissertation. Nautical Archaeology Program. Anthropology Department. Texas A\&M University, EUA.

YAMAFUNE, K. et al. 2016. Multi-Image Photogrammetry to Record and Reconstruct Underwater Shipwrecks. Journal of Archaeology Method and Theory. 23(1).

ZHUKOVSKY, M. O., et al., 2013. Photogrammetric Techniques fo 3-D Underwater Record of the Antique Time Ship from Phanagoria. In: International Archaives of the Photogrammetry, Remote Sensing and Spatial Information Sciences, V. XL-5/W2. XXIV International CIPA Symposium, Strasbourg, France. 